ISSN: 1410-8917

Jurnal Kimia

Sains \&

Aplikasi
Jurnal Kimia Sains dan Aplikasi Journal of Scientific and Applied Chemistry

Journal homepage: http://ejournal.undip.ac.id/index.php/ksa

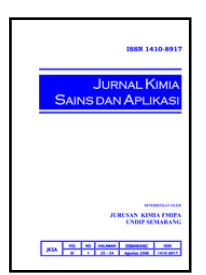

\title{
Pengaruh Variasi Jenis Pelarut pada Rendemen Sintesis Senyawa Kompleks Bis-Asetilasetonatodiaquonikel(II)
}

\author{
Novia Mintari ${ }^{a}$, Suhartana ${ }^{a^{*}}$, Sriatun $^{\mathrm{a}}$ \\ a Inorganic Chemistry Laboratory, Chemistry Department, Faculty of Sciences and Mathematics, Diponegoro University, Jalan Prof. \\ Soedarto, Tembalang, Semarang \\ * Corresponding author: suhartana@live.undip.ac.id
}

\section{Article Info}

Keywords:

Synthesis,

[Ni(acac) $\left.)_{2}\left(\mathrm{H}_{2} \mathrm{O}\right)_{2}\right]$, the variation of solvent, the yield
Kata Kunci:

Sintesis,

[Ni(acac $)_{2}\left(\mathrm{H}_{2} \mathrm{O}\right)_{2}$ ] variasi pelarut, rendemen

\section{Abstract}

Synthesis of Bis-Acetylacetonatodiaquonikel (II) Compound Complex has been performed. This study aimed to synthesize bis-acetylacetonatodiaquonikel(II) $\left(\mathrm{Ni}(\mathrm{acac})_{2}\left(\mathrm{H}_{2} \mathrm{O}\right)_{2}\right)$ complexes by using methanol solvent, ethanol and acetone and comparing the effect of solvents used on the synthesis of complex compounds. Compound complex [ $\mathrm{Ni}(\mathrm{acac})_{2}\left(\mathrm{H}_{2} \mathrm{O}\right)_{2}$ ] was made by modifying the Pawlikowski method with the mole ion ratio of the center with the ligand being 1: 3 . The characterization of complex compounds was performed using Fourier Transform-Infra Red (FT-IR), Atomic Absorption Spectroscopy (AAS), and UV-Vis Spectrophotometer. The FTIR results indicate the presence of a coordinated acetyl acetone group on the central ion of $\mathrm{Ni}^{2+}$ forming the complex $\left[\mathrm{Ni}(\mathrm{acac})_{2}\left(\mathrm{H}_{2} \mathrm{O}\right)_{2}\right]$. The UV-Vis spectra produced the maximum absorption for the complex $\left(\mathrm{Ni}(\mathrm{acac})_{2}\left(\mathrm{H}_{2} \mathrm{O}\right)_{2}\right.$ ] in methanol solvent at a wavelength of $294.5 \mathrm{~nm}$, with a transition energy of $406,720 \mathrm{KJmol}^{-1}$, and a yield of $19.26 \%$. The complex $\left[\mathrm{Ni}(\mathrm{acac})_{2}\left(\mathrm{H}_{2} \mathrm{O}\right)_{2}\right.$ ] in ethanol solvent had a maximum wavelength at $294.5 \mathrm{~nm}$, with a transition energy of $406,72 \mathrm{KJmol}^{-1}$, and a yield of $18.69 \%$. Whereas the complex $\left[\mathrm{Ni}(\mathrm{acac})_{2}\left(\mathrm{H}_{2} \mathrm{O}\right)_{2}\right]$ in the acetone solvent had a maximum wavelength at $293 \mathrm{~nm}$, with a transition energy of $408.80 \mathrm{KJmol}^{-1}$, and a yield of $16.99 \%$.

\section{Abstrak}

Sintesis Senyawa Kompleks Bis-Asetilasetonatodiaquonikel(II) telah dilakukan. Penelitian ini bertujuan untuk untuk mensintesis senyawa kompleks bisasetilasetonatodiaquonikel(II) ([Ni(acac $\left.\left.)_{2}\left(\mathrm{H}_{2} \mathrm{O}\right)_{2}\right]\right)$ dengan menggunakan pelarut metanol, etanol dan aseton serta membandingkan pengaruh pelarut yang digunakan terhadap hasil sintesis senyawa kompleks. Senyawa kompleks $\left[\mathrm{Ni}(\mathrm{acac})_{2}\left(\mathrm{H}_{2} \mathrm{O}\right)_{2}\right.$ ] dibuat dengan memodifikasi metode Pawlikowski dengan perbandingan mol ion pusat dengan ligan adalah 1:3. Karakterisasi senyawa kompleks dilakukan menggunakan Fourier Transform-Infra Red (FT-IR), Atomic Absorption Spectroscopy (AAS), dan Spektrofotometer UV-Vis. Hasil FTIR menunjukkan adanya gugus O pada asetil aseton yang terkoordinasi pada ion pusat $\mathrm{Ni2}+$ membentuk kompleks $\left[\mathrm{Ni}(\mathrm{acac})_{2}\left(\mathrm{H}_{2} \mathrm{O}\right)_{2}\right]$. Spektra UV-Vis menghasilkan serapan maksimum untuk kompleks $\left[\mathrm{Ni}(\mathrm{acac})_{2}\left(\mathrm{H}_{2} \mathrm{O}\right)_{2}\right.$ ] dalam pelarut metanol pada panjang gelombang $294,5 \mathrm{~nm}$, dengan energi transisi sebesar 406,72 KJmol-1, dan rendemen $19,26 \%$. Kompleks [ $\mathrm{Ni}(\mathrm{acac})_{2}\left(\mathrm{H}_{2} \mathrm{O}\right)_{2}$ ] dalam pelarut etanol memiliki panjang gelombang maksimum pada $294,5 \mathrm{~nm}$, dengan energi transisi sebesar 406,72 KJmol-1, dan rendemen 18,69\%. Sedangkan kompleks [ $\mathrm{Ni}(\mathrm{acac})_{2}\left(\mathrm{H}_{2} \mathrm{O}\right)_{2}$ ] dalam pelarut aseton mempunyai panjang gelombang maksimum pada $293 \mathrm{~nm}$, dengan energi transisi sebesar 408,80 KJmol-1, dan rendemen $16,99 \%$. 


\section{Pendahuluan}

Senyawa koordinasi adalah salah satu senyawa yang memegang peranan penting dalam kehidupan manusia. Senyawa ini terbentuk karena adanya ikatan antara ligan yang berperan sebagai donor pasangan elektron (basa lewis) dengan ion pusat (logam) yang berperan sebagai akseptor pasangan elektron (asam lewis). Senyawa koordinasi atau senyawa kompleks terbentuk karena adanya ion logam yang berikatan dengan ligan secara kovalen koordinasi [1].

Kajian dan penelitian tentang sintesis senyawa koordinasi semakin beragam. Salah satunya adalah penelitian tentang senyawa kompleks sebagai katalis. Dari beberapa penelitian telah dilaporkan bahwa senyawa kompleks nikel telah terbukti dapat digunakan pada proses katalitik dalam beberapa reaksi organik seperti reaksi karbonilasi etanol menjadi asam propionat yang menggunakan katalis senyawa kompleks [ $\mathrm{Ni}$ (isoquinoline) $\left.{ }_{4}\right] \mathrm{Cl}_{2}$ dan reaksi hidrogenasi yang mengkonversi glukosa menjadi sorbitol dengan katalis senyawa kompleks [Ni(EDTA $\left.)_{3}\left(\mathrm{NO}_{3}\right)_{2}\right]$ berpendukung silika $\left(\mathrm{SiO}_{2}\right)[2]$.

Atom pusat atau ion logam yang digunakan dalam penelitian ini adalah nikel, sedangkan ligan yang digunakan dalam penelitian ini adalah asetilasetonato karena asetilasetonato berpotensi penting yaitu memiliki sifat dan manfaat dalam bidang farmakologis [3]. Senyawa kompleks asetilasetonato mempunyai sifat adsorpsi yang baik pada logam sehingga dapat digunakan sebagai inhibitor pada logam [4], manfaat lainnya adalah sebagai katalis logam [5]. Ligan asetilasetonato mempunyai atom donor elektron yaitu 2 gugus $\mathrm{O}$ yang terikat pada gugus karbon. Adanya donor elektron dari ligan memungkinkan terjadinya ikatan dengan atom pusat. Atom pusat Ni(II) terikat dengan ligan asetilasetonato pada atom $\mathrm{O}$ secara kovalen koordinasi yaitu $\mathrm{Ni}-\mathrm{O}$.

Penelitian ini dilakukan dengan menggunakan ligan asetilasetonato dengan variasi pelarut yaitu metanol, etanol dan aseton. Berdasarkan variasi pelarut yang digunakan dapat menunjukkan perbedaan hasil rendemen yang diperoleh karena semakin banyak ligan yang terlarut dalam solvent maka akan semakin banyak senyawa kompleks yang terbentuk dan dapat memaksimalkan hasil senyawa kompleks yang terbentuk.

\section{Metode Penelitian}

\section{Alat dan Bahan}

Spektrofotometer Serapan Atom (SSA), Spektrofotometer Inframerah Transformasi Fourier (FTIR), spektrofotometer UV-VIS, neraca analitik, pemanas listrik, pengaduk magnetik, desikator, vakum, dan peralatan gelas Pyrex. $\mathrm{NiCl}_{2} \cdot 6 \mathrm{H}_{2} \mathrm{O}$, asetilasetonato, etanol, metanol, akuades, natrium asetat, aseton, dan Kertas saring whatman 42.

\section{Sintesis Senyawa Kompleks}

Ion pusat sebanyak $10 \mathrm{mmol}\left(2,38\right.$ gram $\left.\mathrm{NiCl}_{2} .6 \mathrm{H}_{2} \mathrm{O}\right)$ dilarutkan dalam $10 \mathrm{~mL} \mathrm{H}_{2} \mathrm{O}$. Kemudian larutan ion pusat dimasukkan ke dalam gelas kimia $100 \mathrm{~mL}$ yang telah diisi dengan larutan yang mengandung $30 \mathrm{mmol}$ asetil aseton dalam $5 \mathrm{~mL}$ variasi pelarut (metanol, etanol, atau aseton). Campuran tersebut diaduk dan segera ditambahkan dengan larutan yang mengandung $30 \mathrm{mmol}$ natrium asetat dalam $5 \mathrm{~mL}$ air, lalu campuran dipanaskan hingga mencapai suhu $80^{\circ} \mathrm{C}$ sambil diaduk beberapa saat kemudian didinginkan.

\section{Pemisahan dan Pemurnian}

Setelah dilakukan pendinginan akan terbentuk endapan yang kemudian disaring dan dicuci dengan akuades lalu dikeringkan dengan vakum. Endapan yang berupa senyawa kompleks tersebut direkristalisasi dengan menggunakan metanol lalu dikeringkan kembali dengan vakum. Dihitung rendemen senyawa kompleks yang terbentuk.

$$
\% \text { Rendemen }=\frac{\text { Bobot kompleks }(\mathrm{g})}{\text { Bobot sampel }(\mathrm{g})} \times 100 \%
$$

\section{Karakterisasi Kompleks}

Karakterisasi senyawa kompleks hasil sintesis dilakukan dengan Spektrofotometer Infrared Tranformasi Fourier (FTIR), Spektrofotometer Serapan Atom (SSA), dan spektrofotometer UV-VIS. Spektrofotometer FTIR digunakan untuk mengukur atau mengetahui adanya gugus fungsional pada senyawa kompleks, serta karakterisasi pada ikatan koordinasi ligan dan ion pusat. Analisis dengan AAS untuk mengetahui berapa banyak atom logam yang terikat dengan ligan dan spektrofotometer UV-VIS untuk mengetahui pergeseran bilangan gelombang karena pengaruh pelarut.

\section{Hasil dan Pembahasan}

Perbandingan mol ion pusat Ni dengan ligan asetilasetonato adalah 1:3. Hasil sintesis logam Ni dengan ligan asetilasetonato dalam pelarut metanol, etanol, dan aseton menghasilkan endapan berwarna biru muda. Bobot dan rendemen senyawa kompleks [Ni(acac $)_{2}\left(\mathrm{H}_{2} \mathrm{O}\right)_{2}$ ] dapat dilihat pada Tabel 1.

Tabel 1: Hasil sintesis kompleks [ $\mathrm{Ni}(\mathrm{acac})_{2}\left(\mathrm{H}_{2} \mathrm{O}\right)_{2}$ ] dalam metanol, etanol,dan aseton.

\begin{tabular}{ccc}
\hline Pelarut & $\begin{array}{c}\text { Berat }\left[\mathrm{Ni}(\mathrm{acac})_{2}\left(\mathrm{H}_{2} \mathrm{O}\right)_{2}\right] \\
\text { (gram) }\end{array}$ & $\begin{array}{c}\% \\
\text { Rendemen }\end{array}$ \\
\hline Metanol & 1,02 & 19,26 \\
Etanol & 0,99 & 18,69 \\
Aseton & 0,9 & 16,99 \\
\hline
\end{tabular}

Kompleks [ $\mathrm{Ni}(\mathrm{acac})_{2}\left(\mathrm{H}_{2} \mathrm{O}\right)_{2}$ ] merupakan kompleks oktahedral (Zahan et al., 2009) high spin complex karena menurut teori ikatan valensi, Ni(II) menyediakan 6 orbital kosong untuk ditempati pasangan elektron bebas dari atom $O$ pada ligan asetilasetonato, orbital tersebut adalah satu orbital $4 \mathrm{~s}$, tiga orbital p, dan 2 orbital d serta ligan asetilasetonato merupakan ligan lemah yaitu ligan 
yang menghasilkan energi medan listrik yang lemah sehingga perbedaan energi antara orbital $\mathrm{t}_{2 \mathrm{~g}}(\mathrm{dxy}, \mathrm{dxz}$ dan dyz) dengan orbital $\mathrm{eg}_{\mathrm{g}}\left(\mathrm{dx}^{2}-\mathrm{y}^{2} \mathrm{dan} \mathrm{dz}^{2}\right)$ kecil atau sangat kecil, akibatnya elektron-elektron akan mengisi kelima orbital $\mathrm{d}$ tanpa berpasangan terlebih dahulu.

Hasil sintesis senyawa kompleks dikarakterisasi menggunakan berberapa instrumen yaitu Spektrofotometer UV-Vis, FTIR, dan AAS.

\section{Spektrofotometer UV-Vis}

Analisis dengan spektrofotometer UV-Vis digunakan untuk menentukan panjang gelombang akibat terjadinya pergeseran panjang gelombang antara ligan dengan atom sebelum dan sesudah beikatan pada kompleks yang terbentuk.

Dari hasil analisis diperoleh bahwa panjang gelombang maksimum senyawa kompleks [Ni(acac $)_{2}\left(\mathrm{H}_{2} \mathrm{O}\right)_{2}$ ] dalam pelarut metanol adalah 294,5 $\mathrm{nm}$, dalam pelarut etanol adalah $294,5 \mathrm{~nm}$, dan dalam pelarut aseton adalah $293 \mathrm{~nm}$. Jika dibandingkan dengan panjang gelombang maksimum $\mathrm{NiCl}_{2} \cdot 6 \mathrm{H}_{2} \mathrm{O}$ dalam akuades yaitu sebesar 396,5 dan $298,0 \mathrm{~nm}$, maka terjadi pergeseran ke arah panjang gelombang yang lebih pendek seperti yang terlihat pada Gambar 1, Gambar 2, Gambar 3, dan Gambar 4. Pergeseran panjang gelombang maksimum kompeks $\left[\mathrm{Ni}(\mathrm{acac})_{2}\left(\mathrm{H}_{2} \mathrm{O}\right)_{2}\right.$ ] dengan senyawa $\mathrm{NiCl}_{2} .6 \mathrm{H}_{2} \mathrm{O}$ sangat kecil, yang mengindikasikan ligan asetil aseton merupakan ligan lemah [6].

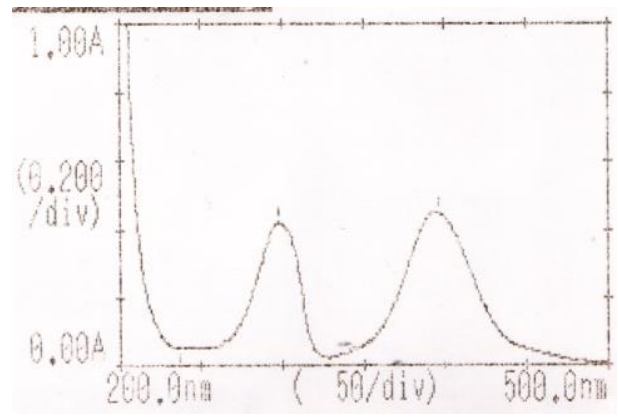

Gambar 1. Hasil analisis $\mathrm{NiCl}_{2} \cdot 6 \mathrm{H}_{2} \mathrm{O}$

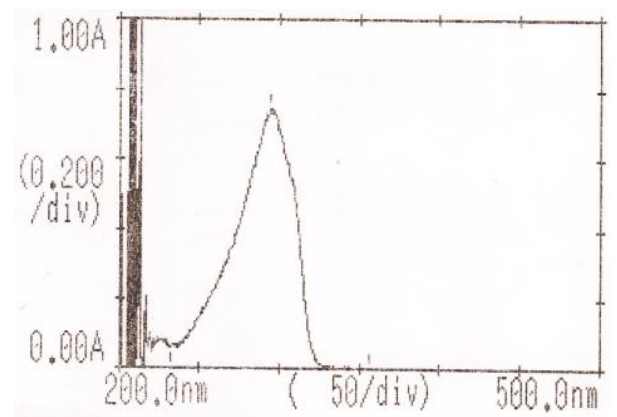

Gambar 2. kompleks [Ni(acac $)_{2}\left(\mathrm{H}_{2} \mathrm{O}\right)_{2}$ ] dalam pelarut metanol

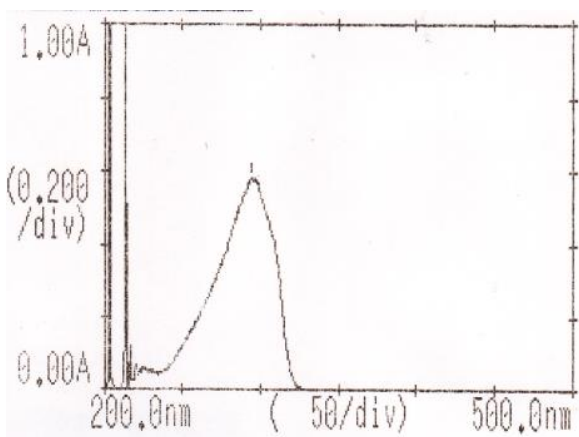

Gambar 3. kompleks [Ni(acac $)_{2}\left(\mathrm{H}_{2} \mathrm{O}\right)_{2}$ ] dalam pelarut etanol

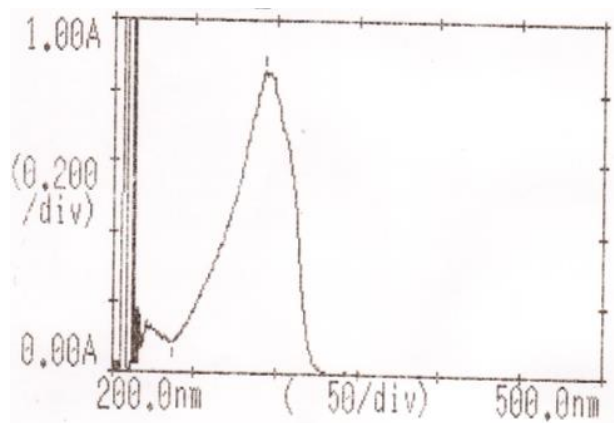

Gambar 4. kompleks [Ni(acac $)_{2}\left(\mathrm{H}_{2} \mathrm{O}\right)_{2}$ ] dalam pelarut aseton

Besarnya energi transisi (10 Dq) kompleks $\left[\mathrm{Ni}(\mathrm{acac})_{2}\left(\mathrm{H}_{2} \mathrm{O}\right)_{2}\right]$ dalam pelarut metanol pada puncak 294,5 nm sebesar 406,7150 $\mathrm{KJmol}^{-1}$, energi transisi (10 Dq) kompleks $\left[\mathrm{Ni}(\mathrm{acac})_{2}\left(\mathrm{H}_{2} \mathrm{O}\right)_{2}\right]$ dalam pelarut etanol pada puncak $294,5 \mathrm{~nm}$ sebesar $406,7150 \mathrm{KJmol}^{-1}$, dan besarnya energi transisi (10 $\mathrm{Dq})$ kompleks $\left[\mathrm{Ni}(\mathrm{acac})_{2}\left(\mathrm{H}_{2} \mathrm{O}\right)_{2}\right]$ dalam pelarut aseton pada puncak 293 nm sebesar 408,7972 $\mathrm{KJmol}^{-1}$. Berdasarkan hasil yang diperoleh menyatakan perbedaan energi antara orbital eg dan $\mathrm{t}_{2 \mathrm{~g}}$ kompleks $\left[\mathrm{Ni}(\mathrm{acac})_{2}\left(\mathrm{H}_{2} \mathrm{O}\right)_{2}\right.$ ] dalam pelarut aseton, etanol, dan metanol tidak terlalu signifikan. Hal ini membuktikan bahwa perbedaan pelarut tidak terlalu berpengaruh pada besarnya energi transisi (10 Dq).

\section{Spektrofotometer FTIR}

Analisis FTIR senyawa kompleks [ $\mathrm{Ni}(\mathrm{acac})_{2}\left(\mathrm{H}_{2} \mathrm{O}\right)_{2}$ ] dilakukan pada bilangan gelombang $300-4000 \mathrm{~cm}^{-1}$ untuk mengetahui gugus fungsi senyawa kompleks dan interaksi yang terjadi antara logam dan ligan. Indikasi terbentuknya senyawa kompleks [ $\mathrm{Ni}(\mathrm{acac})_{2}\left(\mathrm{H}_{2} \mathrm{O}\right)_{2}$ ] yaitu terjadinya pergeseran serapan gugus fungsi kompleks [Ni(acac $)_{2}\left(\mathrm{H}_{2} \mathrm{O}\right)_{2}$ ] dalam pelarut metanol, etanol, dan aseton terhadap ligan asetil aseton yang ditunjukan pada Gambar 5 

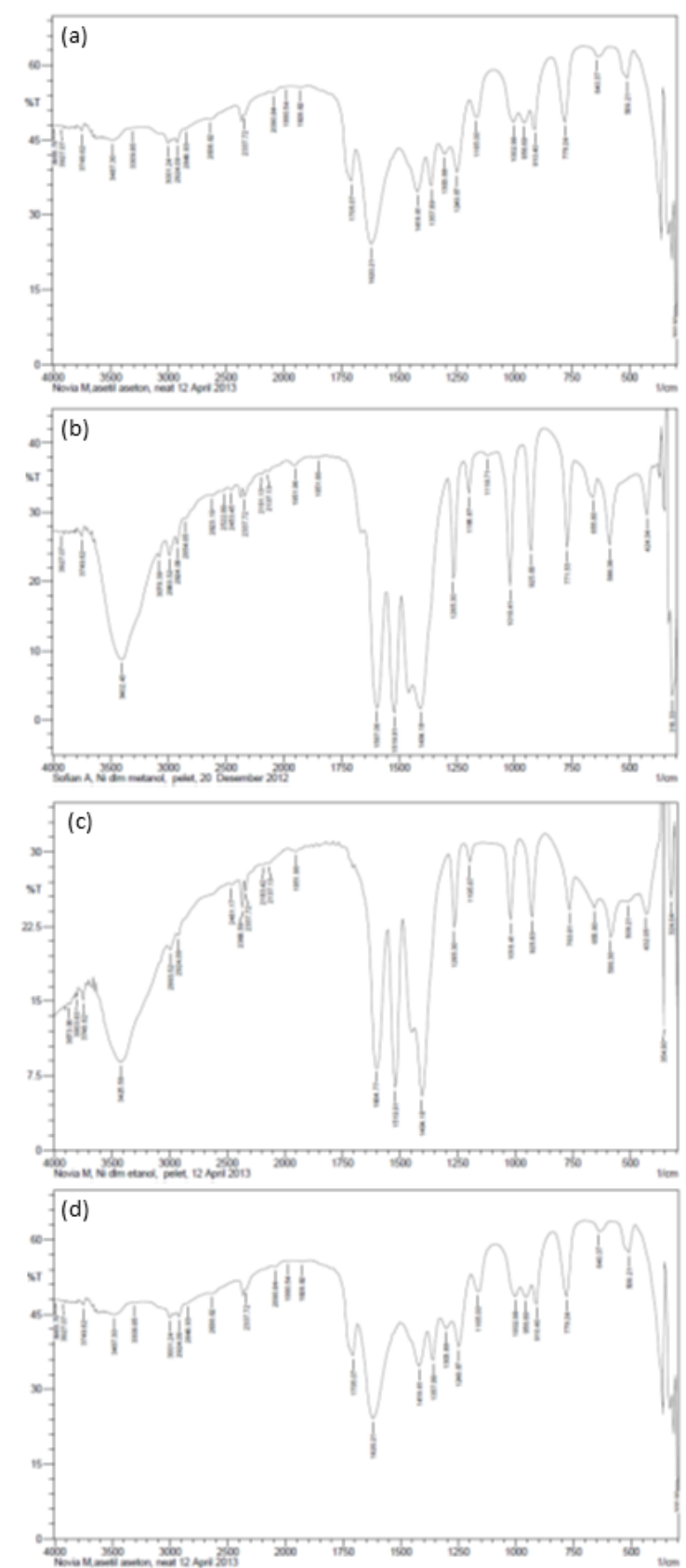

Gambar 5. Spektra (a) ligan asetilaseton, (b) kompleks [Ni(acac $)_{2}\left(\mathrm{H}_{2} \mathrm{O}\right)_{2}$ ] dalam pelarut metanol, (c) etanol, dan (d) aseton.

Berdasarkan hasil analisis ligan asetil aseton dengan FTIR pada Gambar 5, dapat dilihat bahwa terdapat serapan melebar dari $\mathrm{O}-\mathrm{H}$ muncul pada bilangan gelombang 3487,30 $\mathrm{cm}^{-1}$ yang mengindikasikan bahwa ligan asetil aseton mengandung air, sedangkan pada hasil analisis senyawa kompleks [ $\mathrm{Ni}(\mathrm{acac})_{2}\left(\mathrm{H}_{2} \mathrm{O}\right)_{2}$ ] dalam pelarut metanol, etanol dan aseton serapan melebar dan kuat dari gugus $\mathrm{O}-\mathrm{H}$ muncul pada bilangan gelombang $3402,43 \mathrm{~cm}^{-1}$, $3425,58 \mathrm{~cm}^{-1}$ dan $3425,58 \mathrm{~cm}^{-1}$ yang mengindikasikan vibrasi gugus $\mathrm{O}-\mathrm{H}$ cukup kuat dari molekul air yang terikat pada kompleks atau air menjadi ligan yang terikat dalam kompleks (Kashar, 2010). Terjadinya pergeseran serapan gugus fungsi kompleks [Ni(acac $)_{2}\left(\mathrm{H}_{2} \mathrm{O}\right)_{2}$ ] dalam pelarut metanol, etanol, dan aseton terhadap ligan asetilaseton mengindikasikan terbentuknya senyawa kompleks [ $\mathrm{Ni}(\mathrm{acac})_{2}\left(\mathrm{H}_{2} \mathrm{O}\right)_{2}$ ]. Pada spektra hasil analisis ligan asetilaseton, serapan tajam pada bilangan gelombang $3001,24 \mathrm{~cm}^{-1}$ merupakan $\mathrm{C}-\mathrm{H}$ alkana vibrasi ulur, sedangkan pada spektra hasil analisis $\left[\mathrm{Ni}(\mathrm{acac})_{2}\left(\mathrm{H}_{2} \mathrm{O}\right)_{2}\right]$ dalam pelarut metanol, etanol, dan aseton serapan tajam pada bilangan gelombang $3078,39 \mathrm{~cm}^{-1}, 2993,52 \mathrm{~cm}^{-1}$, dan $2993,52 \mathrm{~cm}^{-}$ ${ }^{1}$ merupakan serapan dari $\mathrm{C}-\mathrm{H}$ alkana.

Serapan $\mathrm{C}=\mathrm{O}$ keton dan vibrasi $\mathrm{C}-\mathrm{O}$ yang berasal dari ester pada spektra asetilaseton muncul pada bilangan gelombang $1705,07 \mathrm{~cm}^{-1}$ dan $1357,89 \mathrm{~cm}^{-1}$, sedangkan Serapan $\mathrm{C}=\mathrm{O}$ keton spektra $\left[\mathrm{Ni}(\mathrm{acac})_{2}\left(\mathrm{H}_{2} \mathrm{O}\right)_{2}\right.$ ] dalam pelarut metanol, etanol, dan aseton muncul pada bilangan gelombang 1597,06 $\mathrm{cm}^{-1}, 1604,77 \mathrm{~cm}^{-1}$, dan $1604,77 \mathrm{~cm}^{-1}$. Vibrasi C-O yang berasal dari ester pada spektra kompleks $\left[\mathrm{Ni}(\mathrm{acac})_{2}\left(\mathrm{H}_{2} \mathrm{O}\right)_{2}\right]$ dalam pelarut metanol, etanol, dan aseton muncul pada bilangan gelombang 1285,30 $\mathrm{cm}^{-1}$. Frekuensi vibrasi $\mathrm{C}=\mathrm{O}$ kompleks bis-asetilasetonato bergeser lebih rendah dibandingkan dengan vibrasi gugus $\mathrm{C}=\mathrm{O}$ ligan asetilaseton. Frekuensi vibrasi $\mathrm{C}=\mathrm{O}$ yang rendah ini disebabkan oleh delokalisasi elektron karena terjadi konjugasi dengan ikatan $\mathrm{C}=\mathrm{C}$. Vibrasi $\mathrm{C}-\mathrm{O}$ yang berasal dari ester menunjukkan serapan yang sangat tajam dibandingkan dengan serapan pada ligan bebasnya, hal ini karena vibrasi dari C-O pada senyawa ini terikat pada logam Ni sehingga intensitasnya meningkat.

Pada spektra asetilaseton, serapan tajam pada bilangan gelombang $1620,21 \mathrm{~cm}^{-1}$ merupakan serapan dari $\mathrm{C}=\mathrm{C}$ alkena dan serapan tajam pada bilangan gelombang 1419,61 $\mathrm{cm}^{-1}$ merupakan serapan dari $\mathrm{C}-\mathrm{H}$ alifatik vibrasi tekuk, frekuensi vibrasi $\mathrm{C}-\mathrm{C}$ untuk alkana muncul pada serapan $1249,87 \mathrm{~cm}^{-1}-779,24 \mathrm{~cm}^{-1}$, sedangkan pada spektra $\left[\mathrm{Ni}(\mathrm{acac})_{2}\left(\mathrm{H}_{2} \mathrm{O}\right)_{2}\right]$ dalam pelarut metanol, etanol, dan aseton serapan tajam pada bilangan gelombang $1519,91 \mathrm{~cm}^{-1}$ merupakan serapan dari $\mathrm{C}=\mathrm{C}$ alkena, frekuensi vibrasi $\mathrm{C}-\mathrm{C}$ untuk alkana muncul pada serapan $1195,87 \mathrm{~cm}^{-1}-771,53 \mathrm{~cm}^{-1}$.

Pada spektra hasil analisis [ $\left.\mathrm{Ni}(\mathrm{acac})_{2}\left(\mathrm{H}_{2} \mathrm{O}\right)_{2}\right]$ dalam pelarut metanol, etanol, dan aseton terdapat vibrasi Ni$\mathrm{O}$ dari ligan asetilasetonato yang muncul pada bilangan gelombang 424,34 $\mathrm{cm}^{-1}, 432,05 \mathrm{~cm}^{-1}$, dan 424,34 $\mathrm{cm}^{-1}$. Hal ini sesuai dengan literatur yang menyebutkan bahwa vibrasi logam dengan gugus 0 dari ligan akan muncul pada bilangan gelombang $600-400 \mathrm{~cm}^{-1}[7]$.

Gambar 6 menunjukkan struktur dari senyawa kompleks [ $\mathrm{Ni}(\mathrm{acac})_{2}\left(\mathrm{H}_{2} \mathrm{O}\right)_{2}$ ] yang mempunyai struktur oktahedral. Asetilaseton merupakan ligan bidentat yang dapat menyumbangkan empat pasang elektron bebas kepada ion logam sebagai atom pusat dan ligan $\mathrm{H}_{2} \mathrm{O}$ akan menyumbangkan dua pasang elektron bebas kepada ion logam sebagai atom pusat. Jika ion $\mathrm{Ni}^{2+}$ dengan konfigurasi elektron valensi $3 \mathrm{~d}^{8} 4 \mathrm{~s}^{\circ}$ berinteraksi dengan ligan asetilaseton dan $\mathrm{H}_{2} \mathrm{O}$ maka akan menghasilkan hibridisasi $\mathrm{sp}^{3} \mathrm{~d}^{2}$. Oleh karena itu nikel (II) sebagai atom pusat akan mengikat dua molekul asetilaseton dan dua molekul $\mathrm{H}_{2} \mathrm{O}$ melalui ikatan koordinasi enam gugus $\mathrm{O}$ terhadap atom pusat membentuk struktur senyawa kompleks oktahedral. 
<smiles></smiles>

Gambar 6. Struktur senyawa kompleks $\left[\mathrm{Ni}(\mathrm{acac})_{2}\left(\mathrm{H}_{2} \mathrm{O}\right)_{2}\right]$

\section{Pengaruh Variasi Pelarut}

Filtrat hasil sintesis senyawa kompleks [Ni(acac $)_{2}\left(\mathrm{H}_{2} \mathrm{O}\right)_{2}$ ] dalam pelarut metanol, etanol, dan aseton dianalisis dengan menggunakan AAS untuk mengetahui konsentrasi $\mathrm{Ni}$ sisa dan mengetahui banyaknya atom $\mathrm{Ni}$ sisa yang terikat dengan ligan asetilasetonato. Pemilihan pelarut metanol, etanol, dan aseton karena ligan asetilaseton larut dalam pelarut polar dan semipolar. Hal ini berdasarkan prinsip Like dissolve like yaitu senyawa yang bersifat polar akan larut dalam pelarut polar juga. Penurunan konsentrasi yang terjadi diasumsikan Ni sudah berikatan dengan ligan pada senyawa kompleks. Konsentrasi Ni ditunjukan oleh Tabel 2.

Tabel 2: Hasil analisis logam Ni dengan AAS

\begin{tabular}{cccc}
\hline \multirow{2}{*}{ No } & \multicolumn{2}{c}{ Konsentrasi $\mathrm{Ni}^{2+}(\mathrm{ppm})$} & \multirow{2}{*}{ Pelarut } \\
\cline { 2 - 3 } & Awal & Akhir & \\
\hline 1 & 238000 & 185,48 & Metanol \\
2 & 238000 & 147,89 & Etanol \\
3 & 238000 & 53,42 & Aseton \\
\hline
\end{tabular}

Hasil pengukuran kadar logam Ni dalam filtrat hasil sintesis senyawa kompleks [ $\mathrm{Ni}(\mathrm{acac})_{2}\left(\mathrm{H}_{2} \mathrm{O}\right)_{2}$ ] dengan AAS menunjukan penurunan konsentrasi pada $\left[\mathrm{Ni}^{2+}\right]$ sisa sintesis senyawa kompleks. Semakin semipolar suatu pelarut semakin terlihat penurunan konsentrasi $\mathrm{Ni}$ dan akan semakin besar konsentrasi $\mathrm{Ni}$ yang berikatan dengan ligan asetilaseton.

\section{Kesimpulan}

Sintesis senyawa kompleks logam Ni dengan ligan asetil aseton menghasilkan senyawa kompleks [Ni(acac $)_{2}\left(\mathrm{H}_{2} \mathrm{O}\right)_{2}$ ]. Hasil rendemen senyawa kompleks [Ni(acac $)_{2}\left(\mathrm{H}_{2} \mathrm{O}\right)_{2}$ ] dalam pelarut metanol sebesar $19,26 \%$, dalam pelarut etanol sebesar $18,69 \%$, dan dalam pelarut aseton sebesar $16,99 \%$.

\section{Daftar Pustaka}

[1] Frank Albert Cotton, Geoffrey Wilkinson, Paul L. Gaus, Basic inorganic chemistry, John Wiley, 1995.

[2] Sabine Schimpf, Catherine Louis, Peter Claus, $\mathrm{Ni} / \mathrm{SiO} 2$ catalysts prepared with ethylenediamine nickel precursors: Influence of the pretreatment on the catalytic properties in glucose hydrogenation, Applied Catalysis A: General, 318, (2007) 45-53 http://dx.doi.org/10.1016/j.apcata.2006.10.034

[3] O. O. E. Onawumi, O. A. Odunola, E. Suresh, Parimal Paul, Synthesis, structural characterization and microbial activities of mixed ligand copper(II) complexes of 2,2'-bipyridine and acetylacetonate, Inorganic Chemistry Communications, 14, 10, (2011) 1626-1631

http://dx.doi.org/10.1016/j.inoche.2011.06.025

[4] A Ghanbari, MM Attar, M Mahdavian, Acetylacetonate complexes as new corrosion inhibitors in phosphoric acid media: inhibition and synergism study, Progress In Color, Colorants and Coatings, Volume 2, (2009) 115-122

[5] Clara Pereira, Sónia Patrício, Ana Rosa Silva, Alexandre L. Magalhães, Ana Paula Carvalho, João Pires, Cristina Freire, Copper acetylacetonate anchored onto amine-functionalised clays, Journal of Colloid and Interface Science, 316, 2, (2007) 570-579 http://dx.doi.org/10.1016/j.jcis.2007.07.053

[6] Sukardjo, Kimia koordinasi, PT Bina Aksara, 1985.

[7] Kazuo Nakamoto, Infrared and Raman Spectra of Inorganic and Coordination Compound, Third Edition ed., John Wiley and Sons Inc, New York, 1978. 